\title{
Theory and Application of Linear Supply Function Equilibrium in Electricity Markets
}

\author{
Ross Baldick \\ Department of Electrical and Computer Engineering, The University of Texas at Austin, \\ 1 University Station C0803, Austin, TX 78712-0240 \\ baldick@ece.utexas.edu \\ Ryan Grant \\ Analysis Group, Inc., 2 Embarcardero Center, Suite 1750, San Francisco, CA 94111 \\ Edward Kahn \\ Analysis Group, Inc., 2 Embarcadero Center, Suite 1750, San Francisco, CA 94111 \\ Ekahn@analysisgroup.com
}

\begin{abstract}
We consider a supply function equilibrium (SFE) model of interaction in an electricity market. We assume a linear demand function and consider a competitive fringe and several strategic players having capacity limits and affine marginal costs. The choice of SFE over Cournot equilibrium and other models and the choice of affine marginal costs is reviewed in the context of the existing literature.

We assume that bid rules allow affine or piecewise affine non-decreasing supply functions by firms and extend results of Green and Rudkevitch concerning the linear SFE solution. An incentive compatibility result is proved. We also find that a piecewise affine SFE can be found easily for the case where there are non-negativity limits on generation. Upper capacity limits, however, pose problems and we propose an ad hoc approach.
\end{abstract}


We apply the analysis to the England and Wales electricity market, considering the 1996 and 1999 divestitures. The piecewise affine SFE solutions generally provide better matches to the empirical data than previous analysis.

Keywords: Electricity restructuring, supply function equilibrium, divestitures JEL codes: D43, L13, L51, L94.

\section{INTRODUCTION}

This paper explores the linear version of the supply function equilibrium (SFE) model. The general SFE approach was introduced by Klemperer and Meyer (1989) and applied by Green and Newbery (1992) to the electricity industry reforms in England and Wales (E\&W). Green (1996) used a linear version of this model and applied it to prospective divestitures of generation assets mandated by the regulator of the electricity industry in $\mathrm{E} \& \mathrm{~W}$. We offer a generalization of Green's model and extend the application to subsequent changes in the horizontal structure of the electricity market in $\mathrm{E} \& \mathrm{~W}$, beyond those studied by Green. In particular, we introduce cost heterogeneity, capacity limits, and non-zero marginal cost intercepts into the linear supply function equilibrium framework. We apply these refinements to analyze divestitures in the England and Wales market in the period 1996-1999. Before exploring these issues and describing the England and Wales market, it is worthwhile addressing two threshold questions. First, what does SFE offer beyond the traditional Cournot framework and other alternative models such as multi-unit auction models and agent-based simulations? Second, why use the linear form of SFE rather than the more general formulation?

\subsection{Why Not Cournot?}

SFE competes with the Cournot model as a practical tool for studying oligopoly in the electricity industry. Recent reforms of the electricity industry around the world have stimulated numerous studies of oligopoly behavior in restructured electricity markets. Papers of this kind have been published reflecting issues in Scandinavia, Spain, New 
Zealand, and U.S. electricity markets, particularly California. ${ }^{1}$ All of these papers rely on the Cournot framework.

SFE is attractive compared to Cournot because it offers a more realistic view of electricity markets, where bid rules may require suppliers to offer a price schedule that may apply throughout a day, rather than simply put forth a series of quantity bids over a day. In the Cournot framework, price formation depends exclusively on the specification of the demand curve (and on the specification of a competitive fringe.) The market price is determined by the intersection of the aggregate quantity offered and the demand curve. It is notoriously difficult to specify the market demand curve in electricity, due to low short-run elasticity and inexperience with market competition in electricity. As a result, price predictions from Cournot models are not particularly reliable. ${ }^{2}$

The SFE approach also requires the specification of the dependence of demand on price and therefore is not immune to the problem of sensitivity to specification of the market demand. However, the results from SFE analysis are less sensitive to the dependence of demand on price.

The SFE model formulation also offers the possibility of developing some insight into the bidding behavior of firms. One recent example of this application is the use of the SFE framework by the Market Monitoring Committee of the California Power Exchange (Bohn, Klevorick, and Stalon, 1999).

A final attraction of the SFE model is that it explicitly represents an obligation to bid consistently over an extended time horizon such as a day. Baldick and Hogan (2002) show that SFE prices will be below Cournot prices throughout such a time horizon. In

\footnotetext{
${ }^{1}$ For Scandinavia, see Andersson and Bergman (1995). For Spain, see Alba et al (1999), Ramos et al (1998) and Rivier et al (1999). For New Zealand, see Read and Scott (1996) and Scott (1998). In all three of these countries hydro storage plays an important role. For the US, see Borenstein and Bushnell (1999). US markets typically involve network congestion issues. Network congestion is treated in an oligopoly context by Hogan (1997) and by Borenstein, Bushnell and Stoft (2000).

${ }^{2}$ For example, Frame and Joskow (1998) offer the following observation made in the context of reviewing a particular Cournot model implementation in electricity, "We are not aware of any significant empirical
} 
contrast, the Cournot framework does not represent the obligation to bid consistently. This obligation was important in the England and Wales system that we model.

\subsection{Why Not an Multi-Unit Auction Model?}

Multi-unit auction models are another alternative to the SFE approach. For example, von der Fehr and Harbord (1993) propose a multi-unit auction model with discrete cost and bid steps for the England and Wales market. As with the Cournot model, however, their multi-unit auction model does not directly represent the requirement to bid consistently over a time horizon.

\subsection{Why Not an Agent-Based Model?}

Day and Bunn (2001) describe an agent-based numerical model that models firms as seeking optimal responses to the bids of the other firms. Baldick and Hogan (2002) describe a similar numerical framework. These computational equilibrium approaches involve iterations in the function space of supply functions and have the potential to directly treat capacity constraints, price caps, and other details directly. However, such approaches require significant computational effort and because there is no analytic solution do not provide qualitative insights into bidding behavior. Our interest here is in developing qualitative insights into the effect, over a year, say, of changes in market structure such as divestments of capacity.

\subsection{Why Use the Linear SFE Model?}

In the SFE model, functional forms must be specified for demand, cost, and supply functions. We first discuss demand. A particularly simple form is to assume a "linear" demand function; that is, at each time the demand as a function of price has a non-zero intercept and a constant negative slope. ${ }^{3}$ Assuming that the slope is independent of time

support for the Cournot model providing accurate predictions of prices in any market, let alone an electricity market."

${ }^{3}$ We follow the convention of calling this specification a "linear" demand function although it is more precisely described as "affine." In discussing cost and supply functions, we reserve the word linear for affine functions with a zero intercept. 
greatly simplifies the model. Most authors use linear demand functions with demand slope independent of time. ${ }^{4}$

Next we consider the marginal cost as a function of production. There are a range of possible functional forms. The simplest non-trivial case is an affine function with zero intercept or, equivalently, all cost functions having the same non-zero intercept. Following the literature, we will refer to marginal costs that are affine with zero intercept as "linear" marginal costs.

In some models, there is a competitive fringe as well as strategic firms. The functional form for the strategic firms and the fringe can, in principle, be different. Two significant issues explored here concern whether or not the strategic firms are assumed to all have the same cost functions and whether or not the strategic firms and fringe have maximum capacity limits. Both of these issues are empirically important. In the following, if all strategic firms have the same cost functions and all have the same capacity limits (or there are no capacity limits on the strategic firms) then we will say that the cost functions of the firms are symmetric or that the firms are symmetric. Otherwise, we will call the firms asymmetric.

Finally, consider the supply as a function of price. Again, there are a range of possible functional forms. Typical applications use a form for the supply function that is similar to the assumed form of the (inverse) marginal cost function. If the cost functions are symmetric then the equilibrium supply functions often turn out to be symmetric. ${ }^{5}$

Assuming linear demand and affine marginal costs greatly simplifies the SFE mathematics. For example, Turnbull (1983) analyzes an asymmetric two firm model with linear demand, affine marginal costs, and affine supply functions. The resulting conditions for the SFE are straightforward to solve.

\footnotetext{
${ }^{4}$ A computational advantage of the Cournot framework is that constant elasticity demand curves are straightforward to represent, as in Borenstein and Bushnell (1999), p.302.
} 
Green and Newbery (1992) (GN) generalize the linear demand and linear marginal cost asymmetric two firm model by analyzing strategic firms having quadratic marginal costs. This requires numerical solution of differential equations and is undertaken in the interest of greater realism (p.941). For the duopoly structure examined, GN report results primarily for the case of symmetric strategic firms. As the structure of the electricity industry in E\&W has changed, realism suggests that the symmetry assumption and the duopoly assumption both need to be dropped.

The asymmetric duopoly case is also solved by GN and by Laussel (1992). Neither of the latter two papers require linearity. However, there does not appear to be any other results on asymmmetry beyond the duopoly case for non-linear marginal costs.

The great advantage of the SFE with linear marginal costs over the more general form is the ability to handle asymmetric firms when there are more than two strategic firms. Green (1996) does not emphasize this property, but it turns out to be useful in practice. As noted above, the general SFE requires solving a set of differential equations or iteration in the function space of supply functions. These approaches are sufficiently difficult that most authors typically rely on the case of symmetric firms. For practical applications, the asymmetric case is more interesting. This motivates the use of the linear model for the asymmetric, multiple strategic firm industry we consider.

A final justification of the affine SFE model is that in recent work, Baldick and Hogan (2002) show that when there are no capacity constraints and the firms are symmetric with affine marginal costs, then all the SFEs besides the affine SFE are unstable in the sense that given arbitrarily small perturbations to the supply functions from equilibrium, the best responses of the firms involve larger perturbations from the equilibrium. While this result has not been proven in the general case of asymmetric firms, numerical simulations of asymmetric firms in Baldick and Hogan (2002) suggest that SFEs that are less

\footnotetext{
${ }^{5}$ Klemperer and Meyer (1989) show that if the demand has infinite support then symmetric cost functions imply that the equilibrium is symmetric. With finite demand support, as in the electricity market formulation, a symmetric equilibrium is no longer guaranteed.
} 
competitive than the affine SFE are unstable and therefore unlikely to be observed in practice.

\subsection{Organization of paper}

The remainder of the paper is organized as follows. Section 2 introduces the affine marginal costs case. We characterize the affine SFE and prove an incentive compatibility result regarding the price intercept of the equilibrium supply bids. Section 3 introduces capacity constraints. These have been addressed for strategic firms by GN under the assumption that the cost functions are identical for each firm. We address the case of capacity constraints, both for the strategic firms and fringe, where there are asymmetric costs. This case is more realistic for the England and Wales market subsequent to the 1996 divestiture. We show that this situation is very much more complex than the case of asymmetric costs and capacity constraints in the Cournot framework and propose an ad hoc approach to dealing with the capacity constraints. Section 4 applies these methods to recent structure and price changes in the electricity market in England and Wales. The theoretical issues discussed in Sections 2 and 3 are illustrated by the numerical examples introduced in section 4. Section 5 offers some conclusions.

\section{THE AFFINE MARGINAL COST CASE}

As discussed above, the SFE models reported in the literature typically assume that the bidders' marginal cost functions have zero intercept, or, equivalently, assume that all have a common intercept. This makes the SFE easier to find and was plausible for the coal technology in England and Wales market prior to the 1996 divestitures. For electricity markets with heterogeneous technologies, including gas as well as coal, this assumption is neither plausible nor practically useful.

\subsection{What is Gained}

The requirement that marginal cost functions have zero intercept is compared to where they are allowed to have a positive intercept. We evaluate these two approximations in terms of the more realistic case of piece-wise linear marginal costs. Figure 1 illustrates the two approximations to a typical piece-wise linear marginal cost curve characteristic of 
electricity generation firms. In these curves, we have neglected issues such as start-up and no-load costs of individual generating units owned by a firm and subsumed them into a piece-wise linear firm marginal cost curve. The two approximations to this curve will be used in Section 4 below. If the marginal costs curves are equal at full production, as illustrated in figure 1, then assuming that the marginal costs pass through the origin will over-estimate profits compared to the piece-wise linear function. The line through the origin is likely to be particularly unrealistic when the supply of a firm is from the low end of its capacity. Our examples in Section 4 will show cases of this kind.

We use an affine approximation as in figure 1 that matches the marginal cost at both full and zero production. This affine approximation will typically under-estimate profits, although other affine approximations could be chosen to potentially better estimate profits.

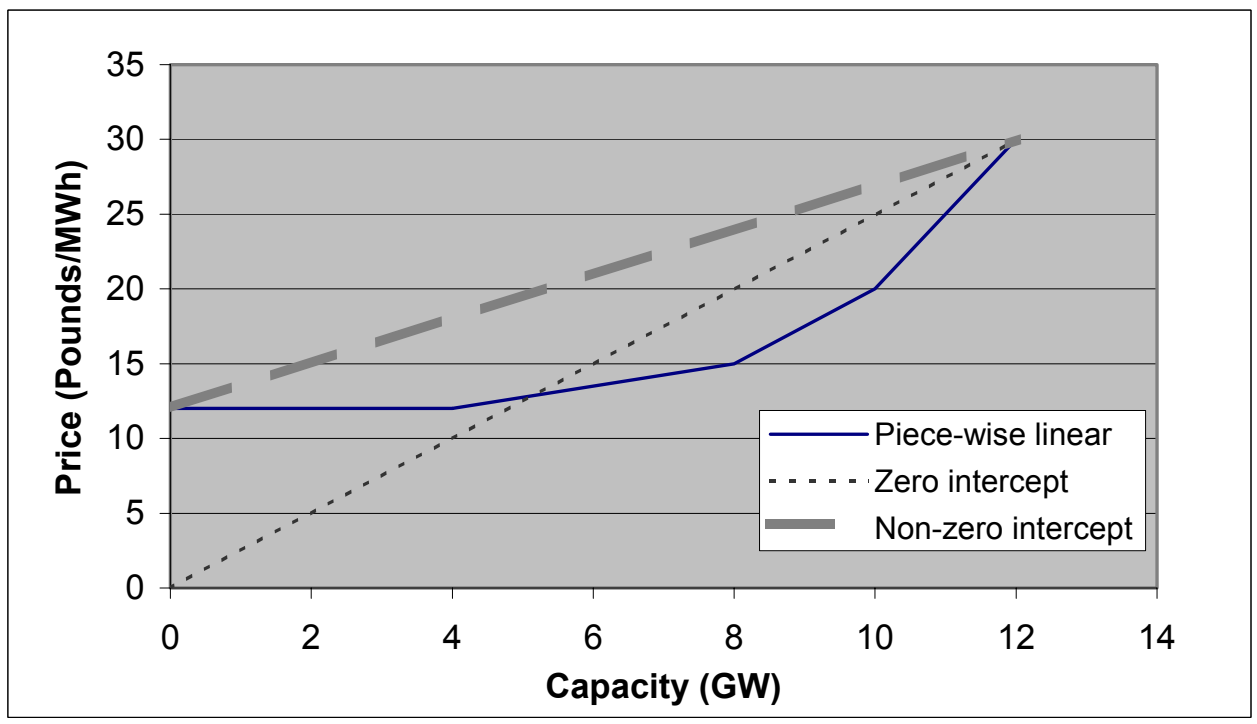

Figure 1: Affine Approximations to a Piece-wise Linear Marginal Cost Curve

\subsection{Formulation}

We begin with the same general form of the demand curve as in Green, namely: 


$$
D(p, t)=N(t)-\gamma p
$$

The underlying load-duration characteristic is specified by the function $N(t)$, which is assumed to be continuous. It represents the variation of demand over a time horizon, during which we assume that the bid supply functions are required to be held constant. The load-duration characteristic is conventionally represented as a non-increasing function and we will assume that the length of the time horizon has been normalized so that it ranges from 0 to 1 . Furthermore, for each time $t$, the demand $D$ is "linear" in $p$ with slope $\mathrm{d} D / \mathrm{d} p=-\gamma$. The coefficient $\gamma$ is assumed to be positive.

The total cost function for firm $i, C_{i}, i=1, \ldots, n$, is given as a strictly concave quadratic function of production. This form results in an affine marginal cost function for each firm:

$$
\begin{aligned}
& \forall i, \forall q_{i} \geq 0, C_{i}\left(q_{i}\right)=1 / 2 c_{i} q_{i}^{2}+a_{i} q_{i}, \\
& \forall i, \forall q_{i} \geq 0, \mathrm{~d} C_{i} / \mathrm{d} q_{i}\left(q_{i}\right)=c_{i} q_{i}+a_{i},
\end{aligned}
$$

with $c_{i}>0$ for each firm $i$ for strictly convex costs. In contrast to previous analysis in the literature, we allow the $a_{i}$ to be non-zero and to be specific to each firm.

We assume that the market rules specify that the supply function of each firm is affine; that is, of the form:

$$
\forall i, q_{i}(p)=\beta_{i}\left(p-\alpha_{i}\right)
$$

The parameters $\alpha_{i}$ and $\beta_{i}$ are chosen by firm $i$ subject to the requirement that $\beta_{i}$ be nonnegative. Strictly speaking, we should modify the supply function (4) so that it is always non-negative; however, we will initially assume that the realized prices over the time horizon are such that no supply functions ever evaluate to being negative. We will 
subsequently revisit this assumption and generalize the allowed form of the supply function to piecewise affine non-decreasing functions.

\subsection{Solution}

Klemperer and Meyer (1989), Green and Newbery (1992), and Green (1996) describe the optimization problem faced by firm $i$ assuming that the supply functions $q_{j}$ of the other firms $j$ remain fixed over the time horizon. The basic equation governing the SFE solution is provided by Green (1996) as his equation (4), which we quote here for reference:

$$
\forall i, q_{i}(p)=\left(p-\mathrm{d} C_{i} / \mathrm{d} q_{i}\left(q_{i}(p)\right)\right)\left(-d D / d p+\sum_{j \neq i} d q_{j}(p) / d p\right) .
$$

If there are no capacity constraints, then any solution to these coupled differential equations such that each $q_{i}$ is non-decreasing over the relevant range of prices is an SFE. Notice that these equations do not involve the load-duration characteristic $N(t)$ but do depend on the demand slope $d D / d p$.

Substituting from (1), (3), and (4) above into Green's equation (4), noting that $\mathrm{d} q_{i} / \mathrm{d} p=$ $\beta_{i}$, we obtain:

$$
\forall i, \beta_{i}\left(p-\alpha_{i}\right)=\left(p-c_{i} \beta_{i}\left(p-\alpha_{i}\right)-a_{i}\right)\left(\gamma+\sum_{j \neq i} \beta_{j}\right)
$$

Assuming that the bid supply function must be consistent across all times, this equation must be satisfied at every realized value of price $p$. If there are at least two distinct values of price that are realized and satisfy (5) then equation (5) is an identity. That is, we can equate coefficients of like powers of $p$ on the left and right hand side of the equation. Equating coefficients of $p$, we obtain Green's equation (6):

$$
\forall i, \beta_{i}=\left(1-c_{i} \beta_{i}\right)\left\{\gamma+\Sigma_{j \neq i} \beta_{j}\right\}
$$

Equating coefficients of the constant terms we obtain: 


$$
\forall i,-\alpha_{i} \beta_{i}=-\left(a_{i}-c_{i} \beta_{i} \alpha_{i}\right)\left\{\gamma+\Sigma_{j \neq i} \beta_{j}\right\}
$$

Both (6) and (7) must be satisfied with non-negative values of $\beta_{i}$ for each firm $i$ for an affine SFE to exist. Substituting from (6) for $\beta_{i}$ for each $i$ into the left hand side of (7) yields:

$$
\forall i,-\alpha_{i}\left(1-c_{i} \beta_{i}\right)\left\{\gamma+\Sigma_{j \neq i} \beta_{j}\right\}=-\left(a_{i}-c_{i} \beta_{i} \alpha_{i}\right)\left\{\gamma+\Sigma_{j \neq i} \beta_{j}\right\}
$$

Since the required solution must satisfy $\forall i, \beta_{i} \geq 0$ then, if $\gamma>0$, we have that $\gamma+\Sigma_{j \neq i} \beta_{j}>$ 0 and we can cancel this factor on both sides. Rearranging the resulting expression yields $\alpha_{i}=a_{i}$ for each firm $i$. Conversely:

- $\quad$ if $\alpha_{i}=a_{i}$ for each firm $i$ and if (6) is satisfied with non-negative $\beta_{i}$,

- then (5) is satisfied and the resulting $\alpha_{i}$ and $\beta_{i}$ specify an affine SFE.

Rudkevich (1999) shows that there is exactly one non-negative solution to (6) and presents an iterative scheme in the special case of all firms having zero intercept (that is, $\forall i, a_{i}=0$ ) for finding the solution to (6). The iterative scheme begins with each firm bidding "competitively." That is, each firm $i$ initially bids supply functions with slopes $\beta_{i}$ $=1 / c_{i}$. Rudkevich shows that if each firm at each iteration updates its value of $\beta_{i}$ so as to find the profit maximizing value for firm $i$, given the values of $\beta_{j}$ for the other firms from the previous iteration, then the sequence of iterates converges to the optimal solution of (6).

In the affine case, we can slightly generalize Rudkevich's scheme to imagine each firm $i$ bidding supply functions specified by the values of $\beta_{i}$ and $\alpha_{i}$ at each iteration, with $\beta_{i}$ and $\alpha_{i}$ chosen by firm $i$ at each iteration to maximize profits given the most recent bid supply functions of the other firms. From the identity following (7), the optimal value of $\alpha_{i}$ at each iteration will satisfy $\alpha_{i}=a_{i}$. Rudkevich's result therefore also provides an explanation for how the firms could arrive at the affine SFE, given that they all begin by 
bidding competitively and update their bids myopically at each iteration based on the most recent bids of the other firms. As discussed by Rothkopf (1999), this update ignores the repeated game aspects of the daily pool.

In Baldick, Grant, and Kahn (2000), Appendix 1, we generalize Rudkevich's result to show that if $n<1+\min _{i}\left(1+c_{i} \gamma \sum_{j} \frac{1}{1+c_{j} \gamma}\right)^{2}$ then Rudkevich's update is a contraction map and so the iterative scheme converges to the unique optimum from any starting point. The condition $n<1+\min _{i}\left(1+c_{i} \gamma \sum_{j} \frac{1}{1+c_{j} \gamma}\right)^{2}$ is always satisfied for $n=1,2$, but for larger values of $n$ it depends on the cost function and demand function. If the condition is satisfied, then Rudkevich's iterative scheme converges to equilibrium even if, for example, some firms begin by bidding competitively while others begin with noncompetitive bids. That is, the unique affine SFE is stable in the function space of affine supply functions.

Since the affine supply function is not dependent on the load-duration characteristic, the same slopes $\beta_{i}$ will apply for any load-duration characteristic. Therefore, we can estimate the profits over a year, say, by considering the yearly load-duration characteristic. That is, although the bids could be changed on a daily basis in the England and Wales pool during the period we consider, we can equivalently use the analysis to calculate a single set of supply functions that apply throughout a year. This allows a significant reduction in computational effort compared to analysis on a day-by-day basis. It also provides a convenient framework for comparing pre- and post-divestiture market structure.

The above discussion and uniqueness result are both predicated on the assumption that bid supply functions are affine and that there are no capacity constraints, either minimum or maximum capacity constraints. We will consider minimum and maximum capacity constraints in subsequent sections. If non-affine supply functions may be bid then there are in general multiple SFEs. However, Baldick and Hogan (2002) show that, in some 
circumstances, non-affine SFEs are unstable in the function space of piecewise continuously differentiable supply functions so that only one of the multiple SFEs would be exhibited in practice.

\subsection{Aggregate demand and supply}

To calculate equilibrium prices over the time horizon, we now consider the aggregate demand and price as a function of time. Summing supply over all firms, we have:

$$
\begin{aligned}
\forall t, N(t)-p p(t) & =\Sigma_{i} \beta_{i}\left(p(t)-a_{i}\right), \\
& =p(t) \Sigma_{i} \beta_{i}-\Sigma_{i} \beta_{i} a_{i},
\end{aligned}
$$

where the sum is over all $i$.

So,

$$
\forall t, p(t)=\left(N(t)+\Sigma_{i} \beta_{i} a_{i}\right) /\left(\Sigma_{i} \beta_{i}+\gamma\right) .
$$

Equation (8) exhibits the equilibrium price at each time in the time horizon in terms of the load-duration characteristic.

\subsection{Incentive compatibility}

The equilibrium condition $\alpha_{i}=a_{i}$ for each firm $i$ means that it is incentive compatible for bidders to reveal the intercepts of their marginal cost functions. Bidding a supply function with any other value of intercept results in less profit for the firm. This generalizes a similar result in Rudkevich (1999), which was proven for the case where marginal costs had intercept $a_{i}=0$. A straightforward economic interpretation of this result is that, at low output levels, the bidders have less motive to exaggerate their cost since they have less infra-marginal capacity than at high output levels. Interestingly, however, the result that $\alpha_{i}=a_{i}$ for each firm $i$ does not rely on low output levels and prices ever being realized. The result only depends on their being at least two, perhaps high, prices being realized. 


\subsection{Low demand and price levels}

As remarked, if prices fall below the value of $a_{i}$ for a firm $i$ then the affine functional form (4) will require negative production, which is outside the region of validity of the cost function specification (2). A minor generalization of the affine supply function would allow for piecewise affine, non-decreasing bid supply functions from each firm. That is, we now assume that the bid rules allow each firm to bid piecewise affine, nondecreasing supply functions.

In practice, electricity markets typically require bid supply functions that are functions from quantity to price. A jump in a supply function of a firm can be interpreted as a block of power offered at constant price. Pool operators typically have discretion to choose any or all of such an offered block to meet demand. That is, if demand crosses aggregate supply at a jump in the supply function then we will assume that the price and quantity are determined by interpolating the quantities at the jump. Abusing the definition of a function slightly, we will also depict (in figure 2) supply functions with this interpolation shown explicitly. That is, we will depict supply "correspondences" where, at points of discontinuity, the "function" is multi-valued.

With the above assumption for price and quantity determination at a jump, we can construct a candidate SFE in piecewise affine supply functions by piecing together several supply functions. In each piece, we use the optimality conditions (6) to evaluate the slope of the supply functions of the firms that are actually generating. ${ }^{6}$ So long as the resulting composite supply functions are all non-decreasing then the function is a candidate for the SFE.

We illustrate this approach for $n=2$ firms and consider piecewise affine supply functions of the form:

\footnotetext{
${ }^{6}$ In fact, we must modify the optimality conditions by recognizing that a piecewise affine supply function is not differentiable at its break-points. However, its directional derivatives exist and for our specification of the slopes we find that Green's equation (4) is satisfied in each direction.
} 


$$
\forall i, q_{i}(p)=\left\{\begin{aligned}
0, & \text { if } p \leq a_{i}, \\
\beta_{i}\left(p-a_{i}\right), & \text { if } a_{i} \leq p \leq p^{\prime}, \\
\beta_{i}^{\prime}\left(p-a_{i}\right), & \text { if } p>p^{\prime},
\end{aligned}\right.
$$

where $p^{\prime} \geq a_{i}$ is an appropriate break - point and $\beta_{i}$ and $\beta_{i}^{\prime}$ specify the slopes of the supply functions in the regions $a_{i} \leq p \leq p^{\prime}$ and $p>p^{\prime}$, respectively.

The price intercept at $a_{i}$ for firm $i$ reflects the fact that for prices below this level it cannot be optimal for firm $i$ to produce anything. ${ }^{7}$ Let us assume that $a_{1}<a_{2}$ and seek the location of the break-point $p^{\prime}$ in each supply function. Notice that for prices up to $a_{1}$ there will be no production by either firm.

For prices between $a_{1}$ and $a_{2}$, only firm 1 will generate. For this range of prices, we can consider the SFE where firm 1 is the only firm. Substituting into (6) yields $\beta_{1}=\frac{\gamma}{1+c_{1} \gamma}$. Also, $\beta_{2}=0$, since firm 2 is not producing in this region. These values apply for prices up to $a_{2}$. That is, the higher break-point in equation (9) is at $p^{\prime}=a_{2}$ for this example.

At higher prices than $p^{\prime}=a_{2}$, both firms will generate and the resulting equilibrium slopes of the demand functions are given by the simultaneous solutions of: $\beta_{1}{ }^{\prime}=\frac{\gamma+\beta_{2}{ }^{\prime}}{1+c_{1}\left(\gamma+\beta_{2}{ }^{\prime}\right)}$ and $\beta_{2}{ }^{\prime}=\frac{\gamma+\beta_{1}{ }^{\prime}}{1+c_{1}\left(\gamma+\beta_{1}{ }^{\prime}\right)}$. By writing the conditions in this way, Baldick, Grant and Kahn (2000), lemma 1 shows that $\beta_{1}{ }^{\prime} \geq \beta_{1}$ and $\beta_{2}{ }^{\prime} \geq \beta_{2}$.

Because $\beta_{1}{ }^{\prime} \geq \beta_{1}$ and $\beta_{2}{ }^{\prime} \geq \beta_{2}$, the resulting piece-wise affine supply functions of the form (9) are non-decreasing, as illustrated in figure 2 for a firm $i$. In figure 2 , the price intercept is at $a_{i}=£ 6 / \mathrm{MWh}$, while the break-point is at $p^{\prime}=a_{2}=£ 12 / \mathrm{MWh}$. (For firm 2, supply stays at zero between $p=£ 6 / \mathrm{MWh}$ and $p=£ 12 / \mathrm{MWh}$ since $\beta_{2}=0$.)

\footnotetext{
${ }^{7}$ We are ignoring issues such as start-up costs.
} 
If there is more than one firm with a low price intercept and if prices below the breakpoint $p^{\prime}$ are realized then our construction fails because an undercutting strategy will disrupt the equilibrium. In particular, the two cheaper firms will undercut each other below the price $p^{\prime}$. Numerical simulations in Baldick and Hogan (2002), however, suggest that a qualitatively similar but "smoothed off" SFE in piecewise affine supply functions exists. Moreover, the profits of the smoothed off SFE are very similar to the profits calculated from the supply functions as in figure 2 for the cases considered in Baldick and Hogan (2002). In practice, for the coal and gas technologies we consider, the prices stay above the higher gas intercept and consequently only prices corresponding to the higher slope region are realized.

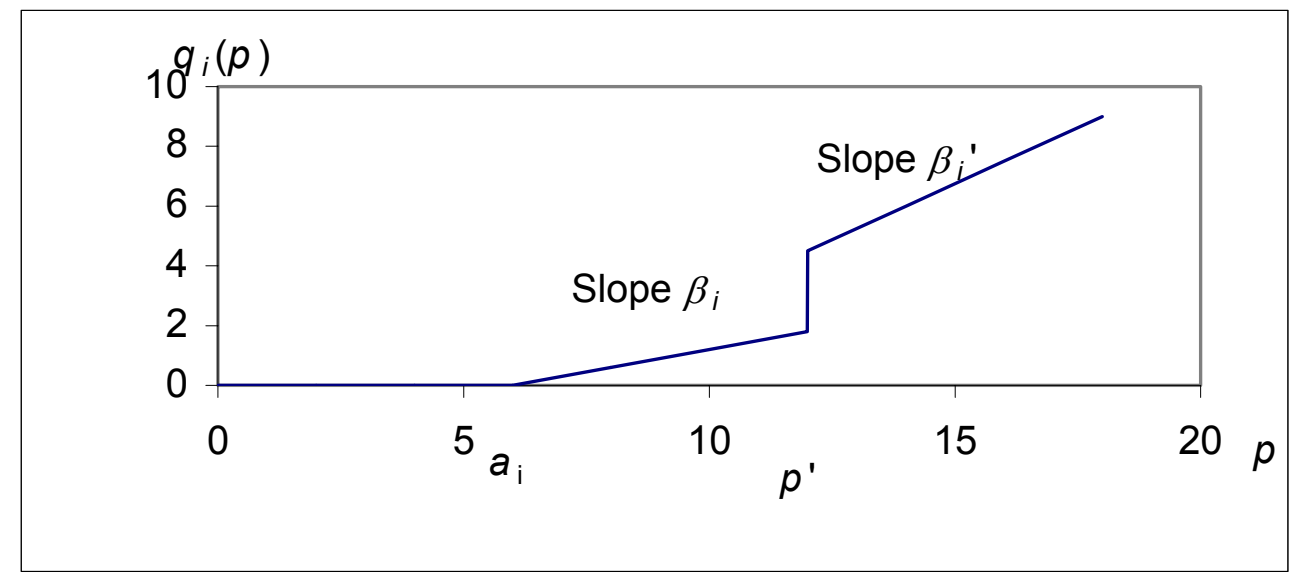

Figure 2: Illustration of piecewise affine, non-decreasing supply function.

\section{MAXIMUM CAPACITY CONSTRAINTS}

In the application discussed in Section 4, we encounter maximum capacity constraints on price-taking bidders. (Similar issues apply in representing maximum capacity constraints on the output of strategic firms.) Green and Newbery (1992) discuss how to treat capacity constraints when cost functions are identical amongst firms. However, their arguments do not appear to generalize to the case where firms have asymmetric costs. We take a different approach here. 
We use the function $D_{r}$ to represent the residual demand resulting from a price taking fringe with capacity constraints. The price taking fringe bids supply functions that reflect their marginal cost and this can be used to solve for the residual demand, eliminating the fringe players from the solution process. Following Bushnell (1998), if the demand is linear then the resulting residual demand $D_{r}$ can be modeled as a piecewise linear function. In particular, if the marginal cost of the fringe at its full production is $p^{\prime}$ then there are $\gamma$ and $\gamma^{\prime}$ such that:

$$
-\frac{d D_{r}}{d p}=\left\{\begin{array}{l}
\gamma, \text { if } p \leq p^{\prime}, \\
\gamma^{\prime}, \text { if } p>p^{\prime} .
\end{array}\right.
$$

The slope $\gamma^{\prime}$ for prices above $p=p^{\prime}$ is due to the demand alone when the fringe is at capacity, while the composite slope $\gamma$ for prices below $p=p^{\prime}$ is due to the combined effect of demand and the competitive fringe when the fringe is also marginal. (See Bushnell (1998) section 4 for derivation of this functional form for the residual demand.) We have that $0<\gamma^{\prime}<\gamma$. That is, the combination of demand and marginal fringe capacity is more elastic than when the fringe is at its capacity.

A straightforward approach to this case would be again to posit a candidate SFE in piecewise affine functions of the form (9) as we did in the previous section. We solve for the slopes of the supply functions in each piece using (6) with the appropriate demand slope for the piece. In contrast to the case considered in the previous section, however, it will be the case that $\beta_{i}^{\prime}<\beta_{i}$ because of the relationship between $\gamma$ and $\gamma^{\prime}$. This means that the candidate supply functions so constructed will not be non-decreasing. In particular, there is a drop in the supply at $p=p^{\prime}$.

The drop in the supply function violates typical pool rules. Moreover, even if the pool rules were to allow such bid supply functions, there can be two intersections of the demand and aggregate supply curve. It is not clear that one of the intersections would be preferred by all of the firms to the other intersection. The profit function of each firm can have two local maxima, one in each of the two price regions, $p \leq p^{\prime}$ and $p \geq p^{\prime}$. 
Different firms may have their global maximum in different regions. That is, the proposed supply functions may not be an equilibrium even under the (unrealistic) assumption that non-monotonic supply functions were allowed. A similar observation about profit functions was made in Bushnell (1998).

If we knew a priori that demand (and prices) were "low" then we could delete the part of the supply functions for $p \geq p^{\prime}$. On the other hand, if we knew that the demand and prices were "high" we could delete the part of the supply function for $p \leq p$ '. This latter approach was taken by Green (1996) in modeling the fringe in the British pool.

However, our interest is in the case where we anticipate that price will vary from below $p^{\prime}$ to above $p^{\prime}$. Unless the price "jumps" from below $p$ ' to above $p^{\prime}$, we are faced with deciding on a strategy for values of price near to $p^{\prime}$. Unlike Green's equation (4), which made no reference to the load-duration characteristic $N(t)$ of the demand, conditions for an equilibrium in piecewise affine supply functions requires knowledge of the range of $N(t)$. Day and Bunn (2001) and Baldick and Hogan (2002) take an iterative computational approach to seeking the equilibria in the presence of constraints. They make use of explicit knowledge of the load-duration characteristic $N(t)$.

Here, instead, as an ad hoc approach that avoids the need to specify $N(t)$, we propose a non-decreasing approximation to the previous piecewise affine function. For prices $p>$ $p^{\prime}$ we maintain the functional form $\beta_{i}^{\prime}\left(p-a_{i}\right)$ where the $\beta_{\mathrm{i}}^{\prime}$ satisfy (6) for demand slope equal to $-\gamma^{\prime}$. For prices $p$ significantly below $p^{\prime}$ we maintain the functional form $\beta_{i}\left(p-a_{i}\right)$ where the $\beta_{i}$ satisfy (6) for demand slope $-\gamma$. For prices between $p=p^{\prime}$ and a price $p_{i}^{\prime \prime}<$ $p^{\prime}$ we posit a joining segment having zero slope. The price $p_{i}$ " is chosen to make the composite supply function continuous. That is, we posit a supply function of the form: ${ }^{8}$

\footnotetext{
${ }^{8}$ It is also possible to consider a supply function that matches the functional form $\beta_{i}\left(p-a_{i}\right)$ at $p=p^{\prime}$ by modifying the function for prices above $p^{\prime}$. However, this results in a greater supply and it is presumably in all the strategic players interests to keep supply lower.
} 


$$
\forall i, q_{i}(p)=\left\{\begin{array}{cc}
\beta_{i}\left(p-a_{i}\right), & \text { if } p \leq p_{i} ", \\
\beta_{i}^{\prime}\left(p^{\prime}-a_{i}\right), & \text { if } p_{i} "<p \leq p^{\prime}, \\
\beta_{i}^{\prime}\left(p-a_{i}\right), & \text { if } p>p^{\prime} .
\end{array}\right.
$$

This makes the supply function constant between $p_{i}$ " and $p^{\prime}$ and guarantees that the supply function is non-decreasing.

Figure 3 illustrates this supply function with $a_{i}=£ 6 / \mathrm{MWh}, p_{i}^{\prime \prime}=£ 10.4 / \mathrm{MWh}$, and $p^{\prime}=$ $£ 12 / \mathrm{MWh}$. In Baldick, Grant and Kahn (2000), an approach is discussed for calculating a non-zero slope for the joining segment that matches the slope of the solution of Green's equation (4) for prices infinitesimally below the price $p^{\prime}$.

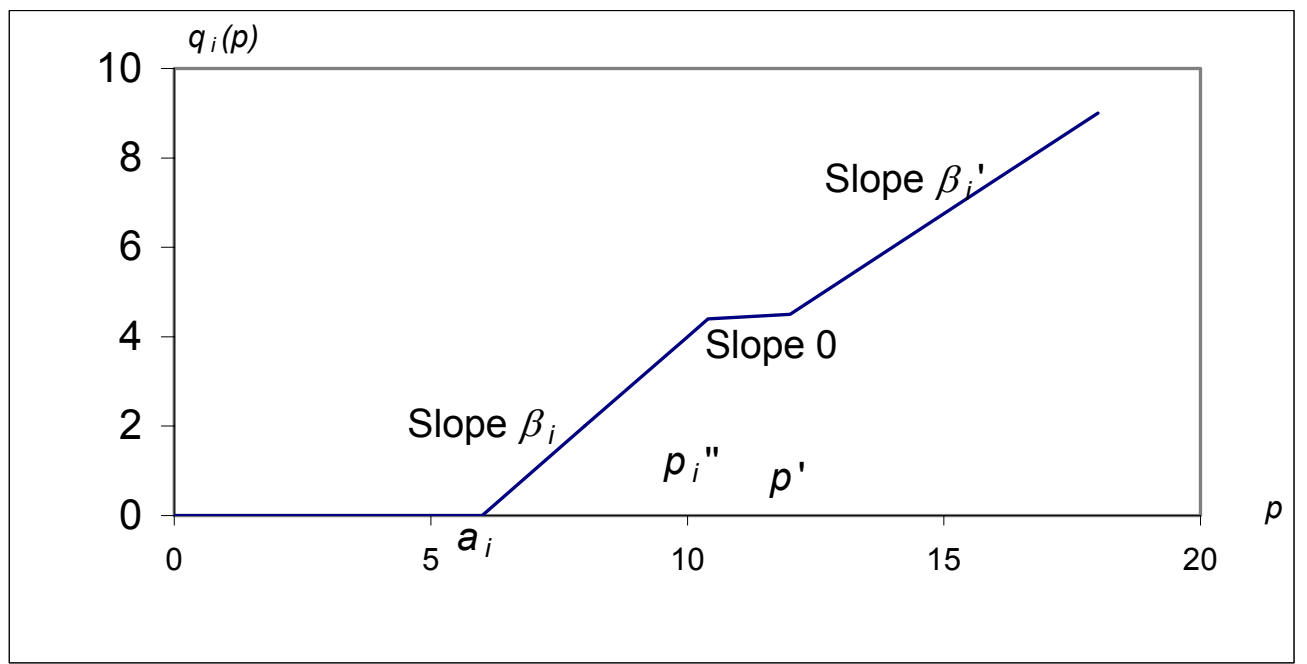

Figure 3: Illustration of supply function (11). 
We emphasize that the set of supply functions in (11) cannot be an equilibrium in nonlinear supply functions since for prices sufficiently below $p^{\prime}$ but above $p_{i}$ " the suggested demand slopes cannot satisfy Green's equation (4). Moreover, the values of the $p_{i}$ " will differ from firm to firm so that the joining segments will not span the same ranges of prices. Nevertheless, we claim that the general form of this supply function is a reasonable one in practice, for three basic reasons.

The first reason is that, for the cases considered in section 4, we discretize the time dimension fairly coarsely. Under these circumstances, we find that prices near to the break-point price $p^{\prime}$ do not arise for the cases we consider. That is, the price does "jump" from well below $p^{\prime}$ to well above $p^{\prime}$ and the value of the supply function is irrelevant in the vicinity of $p^{\prime}$.

The good fortune that prices near to $p^{\prime}$ are not realized is partially an artifact of the coarseness of our time discretization. That is, we must in general consider the case where prices are realized that are in the vicinity of $p^{\prime}$. If the duration of time when $p_{i}{ }^{\prime \prime}<p \leq p^{\prime}$ is relatively small then the effect on profits is also small. In the cases we consider this interval of prices is very small.

Ultimately, this argument points to the fact that in the case of capacity constraints, it is not possible to find an optimal strategy that is independent of the range of the loadduration characteristic $N(t)$. That is, the choice of the slopes in the piecewise affine functions will be affected by whether or not prices are realized in the vicinity of the break-point price. For firms faced with making a decision about their supply functions, the lack of optimality may be relatively inconsequential because it is likely to persist over a relatively short time. We will see that this is true for the cases considered in section 4 .

The third reason for the reasonableness of the choice of supply functions is that calculation of the optimal response by a firm $i$ requires estimation of the slope of the aggregate supply function of the rest of the firms. Generalizing the discussion in Rudkevich (1999), we can imagine firm $i$ fitting a piece-wise affine curve to the observed 
aggregate supply function. If the price $p^{\prime}$ where the fringe reaches capacity is known publicly, then it is reasonable for firms to estimate different slopes for the parts of the supply function above and below price $p=p^{\prime}$. It may even be reasonable for firms to estimate slopes for prices above $p^{\prime}$, well below $p^{\prime}$, and in the vicinity of $p^{\prime}$ as required for the functional form in (11). However, if only a few data points are observed it will not be possible to estimate parameters of functional forms with a large number of parameters. That is, piecewise affine functions with known break-points may be a practical limit to the ability to estimate functions. As mentioned in section 2, at least some of the breakpoints are common knowledge.

\section{APPLICATIONS}

In this section we show how to apply the previous results to modeling the price effects of structural change in the E\&W electricity market. Our objective is to illustrate how the SFE enhancements described in Sections 2 and 3 improve the numerical fit of such models to actual market experience. We begin by characterizing the structural changes in the $\mathrm{E} \& \mathrm{~W}$ electricity market and describing the fitting of the observed demand curves. Next, we briefly reconsider Green's forecast of the effects of divestitures made by National Power (NP) and Power Gen (PG) in 1996. This discussion illustrates the importance of fitting the demand curve properly and the role of capacity constraints.

We then examine the effect of the 1999 divestitures of National Power (NP) and Power Gen (PG). We show that a linear SFE that uses zero cost intercepts for the strategic firms will predict prices that are too low in the post-divestiture case. We also consider two special issues in this context. First we examine the role of "earn out" payments as an explanation of post-1996 pricing behavior. Finally we illustrate the effect of fringe capacity constraints on the supply curves of strategic firms, showing that the size of this effect is small, as argued above. Table 1 summarizes the structure of the cases examined in this section. 
Table 1: Cases Examined and Their Features

\begin{tabular}{|l|l|c|c|}
\hline & Model Features & Structural Change & table or figure \\
\hline 1996 & Strategic Firm Capacity Limits & Two firms $\rightarrow$ Three & table 4 \\
Divestitures & Demand Curve Specification & Firms & \\
\hline 1999 & Positive vs. Zero Intercept & Three Firms $\rightarrow$ Five & tables 5, 6, 7 \\
Divestitures & & Firms & \\
\hline & & Earn Out & table 8 \\
\hline & Maximum Capacity Limits & & figure 5 \\
\hline
\end{tabular}

\subsection{The E\&W Electricity Market}

Market power has been a constant theme in the regulation of the electricity industry in England and Wales. ${ }^{9}$ This has motivated regulatory intervention and responses by both incumbents and entrants. The two dominant generators, National Power (NP) and Power Gen (PG), have retired very substantial amounts of capacity, invested in new combined cycle gas turbines (CCGTs) and been required to divest generation to new entrants. Additional entry has come primarily from CCGT projects. Nuclear output also grew over time. All of this change on the supply side occurred in the face of very sluggish growth in demand (about 1.5\% per year in the late 1990s). Table 2 summarizes the changes in capacity by ownership category over the period 1995-1999, with some comments about the previous history. This table forms the capacity basis for the linear supply function equilibrium (LSFE) estimates reported below.

Table 2: Supply Mix by Firm and Fuel Type

\begin{tabular}{|l|l|c|c|c|}
\hline Category & Comment & MW & MW & MW \\
\hline
\end{tabular}

\footnotetext{
${ }^{9}$ For recent statements of these issues see Offer $(1998,1999)$ and Newbery $(1995,1999)$ among others.
} 


\begin{tabular}{|l|l|c|c|c|}
\hline & & $95-96$ & $98-99$ & $99-00$ \\
\hline Nuclear & $\begin{array}{l}\text { British Energy + } \\
\text { Magnox Electric }\end{array}$ & 10519 & 10519 & 10519 \\
\hline Interconnector & France +Scotland & 3200 & 3200 & 3200 \\
\hline IPP & & 5000 & 7339 & 9721 \\
\hline Eastern & $\begin{array}{l}29 \text { GW @ Vesting + } \\
3 \text { GW CCGT - } \\
\text { retirements and sales }\end{array}$ & 23000 & 16236 & 12291 \\
\hline National Power & $\begin{array}{l}19 \text { GW @ Vesting } \\
+3 \text { GW CCGT - } \\
\text { retirements and sales }\end{array}$ & 18845 & 15865 & 11421 \\
\hline Power Gen & w/o IPPs & & 6700 \\
\hline AES & w/o First Hydro & & & 3954 \\
\hline Edison Mission Energy & & & \\
\hline
\end{tabular}

Nuclear generation expanded in 1994 when Sizewell B, the last nuclear plant constructed in E\&W came into service. In 1996, the government owned Nuclear Electric was restructured into the privatized British Energy and Magnox Electric, which remains in government hands.

Independent power producers (IPPs) all rely on combined cycle gas turbine (CCGT) technology. In the first "dash for gas" from 1991-1993, IPPs contracted with regional distributors (Newbery, 1999, p.224f). By 1995 about 5000 MW of IPP capacity was operating. Table 2 shows that this nearly doubled by 1999.

Table 2 also indicates substantial reductions in capacity by NP and PG over the 1990s. When NP and PG were first created in 1989, NP had 29,486 MW and PG had 19,802 MW (Newbery, 1999, p.202). Each added about 3,200 MW of CCGT capacity and together the two firms retired more than 20,000 MW. ${ }^{10}$ These retirements were in

\footnotetext{
${ }^{10}$ According to NGC (1999) there were 15,152 MW of "Disconnections" between 1991 and 1999 (see table
} 3.11 and $5328 \mathrm{MW}$ of "Decommissionings" (see table 3.12) for NP and PG together. 
addition to divestitures of more than $6000 \mathrm{MW}$ to Eastern ${ }^{11}$ in 1996 and the 1999 divestitures to AES and Edison Mission Energy indicated in table 2. ${ }^{12}$

Table 3 shows the cost and availability assumptions used in our calculations. The cost intercept is assumed to be zero for Nuclear and the Interconnector, a common intercept of $£ 12 / \mathrm{MWh}$ is assumed for the generators with coal-fired plant only (Eastern, AES and EME) and $£ 8 /$ MWh for generators with CCGT plant (IPP, NP, and PG). These marginal cost estimates are based on Bunn and Day (1999). ${ }^{13}$ The cost at maximum capacity follows Green (1996) for generators with thermal plant. These costs can be thought of as either simple cycle turbine costs or the costs of coal plant running very few hours and recovering start up and no load costs over that short period.

The availability estimates in table 3 for all fossil fuel generators are generic. The estimates for nuclear are set to reproduce recent production levels. The high availability for the Interconnector reflects the multiplicity of resources available from Scotland and France.

The cost and availability data in table 3 are combined to produce the cost slope parameters $c_{i}$ that are used to solve for the equilibrium prices and mark-ups. These parameters also depend upon the capacity of each firm. The appendix gives the numerical values used in the results reported below.

\footnotetext{
${ }^{11}$ These assets were subsequently sold to Texas Utilities (TXU).

${ }^{12}$ Edison Mission Energy's First Hydro pumped storage capacity is omitted from table 2 because some fraction of that capacity is devoted to supplying reserves and therefore is not in the energy market. The remaining capacity has uncertain input costs and is therefore difficult to model.

${ }^{13} \mathrm{GN}$ use $£ 18.5 / \mathrm{MWh}$ as the intercept of the marginal cost function for coal plant (p.942), based on coal prices quoted in generators' prospectuses when first privatized in 1991. In the years since the flotation of $\mathrm{NP}$ and PG, coal and gas prices have declined substantially.
} 
Table 3: Cost and Availability Parameters

\begin{tabular}{|l|c|c|c|}
\hline Category & Availability & $\begin{array}{c}\text { Cost Intercept } \\
(\mathfrak{f} / \mathrm{MWh})\end{array}$ & $\begin{array}{c}\text { Cost at Maximum } \\
\text { Capacity (£/MWh })\end{array}$ \\
\hline Nuclear & $83.0 \%$ & 0 & 10.00 \\
\hline Interconnector & $98.0 \%$ & 0 & 10.00 \\
\hline IPP & $85.0 \%$ & 8.00 & 14.00 \\
\hline Eastern & $85.0 \%$ & 12.00 & 30.00 \\
\hline National Power & $85.0 \%$ & 8.00 & 30.00 \\
\hline Power Gen & $85.0 \%$ & 8.00 & 30.00 \\
\hline AES & $85.0 \%$ & 12.00 & 30.00 \\
\hline Edison Mission Energy & $85.0 \%$ & 12.00 & 30.00 \\
\hline
\end{tabular}

\subsection{Fitting Demand Curves}

A major problem associated with practical use of both SFE and Cournot models is the representation of demand. The plausibility of price forecasts with these models depends substantially on how the demand curve is specified. Although there is little demand-side response in the $\mathrm{E} \& \mathrm{~W}$ market, low values of demand elasticity have typically yielded poor fits to the observed data. For example, when GN used very low slopes for the linear demand curve they estimated prices that were very much higher than what was subsequently observed. Even at a high slope $(-0.5 \mathrm{GW} /(\mathfrak{£} / \mathrm{MWh}))$ the predicted prices are much higher than what was observed.

A significant part of the problem of representing demand involves how the demand curve is "anchored" in price-quantity space. GN use an estimate of pre-competition marginal costs and production to anchor their demand curve. Green (1996) uses a demand curve in the form of Eq. (1) above, with $N(t)$ specified as a cubic load duration curve and a slope parameter of $-0.5 \mathrm{GW} /(\mathfrak{f} / \mathrm{MWh})$. This value is considerably higher than what other authors use. GN use 0.25 as their "central" case; Bushnell (1998) uses 0.1; Bunn and Day 
(1999) use values between 0.01 and 0.10 . We will follow GN and report cases for demand slopes of $0.5,0.25$ and 0.1 .

Our procedure takes advantage of the Pool price history. Figure 4 shows both the load duration curve and the price duration curve for 1998-99. The prices shown in this figure are the System Marginal Price (SMP). ${ }^{14}$ Vertically aligned pairs of values of load and price correspond to the same times. Using the data in figure 4 yields a (time) average demand of $33.5 \mathrm{GW}$ and a (time) average price of 23.7 pounds per MWh. (All subsequent reported averages will also be averaged over time.)

We use the data in figure 4 to anchor the demand curves used in our simulations. The anchor point for each of the nine periods we consider is taken to be the $(p, q)$ pair corresponding to the period's midpoint. ${ }^{15}$ This procedure assumes that past price behavior represents a set of expectations that is familiar to strategic firms and apparently acceptable to regulators at that time. The data in this figure are used as the starting point for the iterative solution to Eq. (11). The actual solutions will produce price-quantity pairs that are close to, but not identical with figure 4 .

\footnotetext{
${ }^{14} \mathrm{We}$ ignore other price elements, i.e. the uplift and capacity charges.

${ }^{15}$ The time periods are equal in length with midpoints at $\mathrm{t}=0.056,0.167,0.278,0.389,0.500,0.611,0.722$, 0.833 , and 0.944 for our periods 1 through 9 , respectively.
} 
Figure 4: Load \& Price Duration Curves

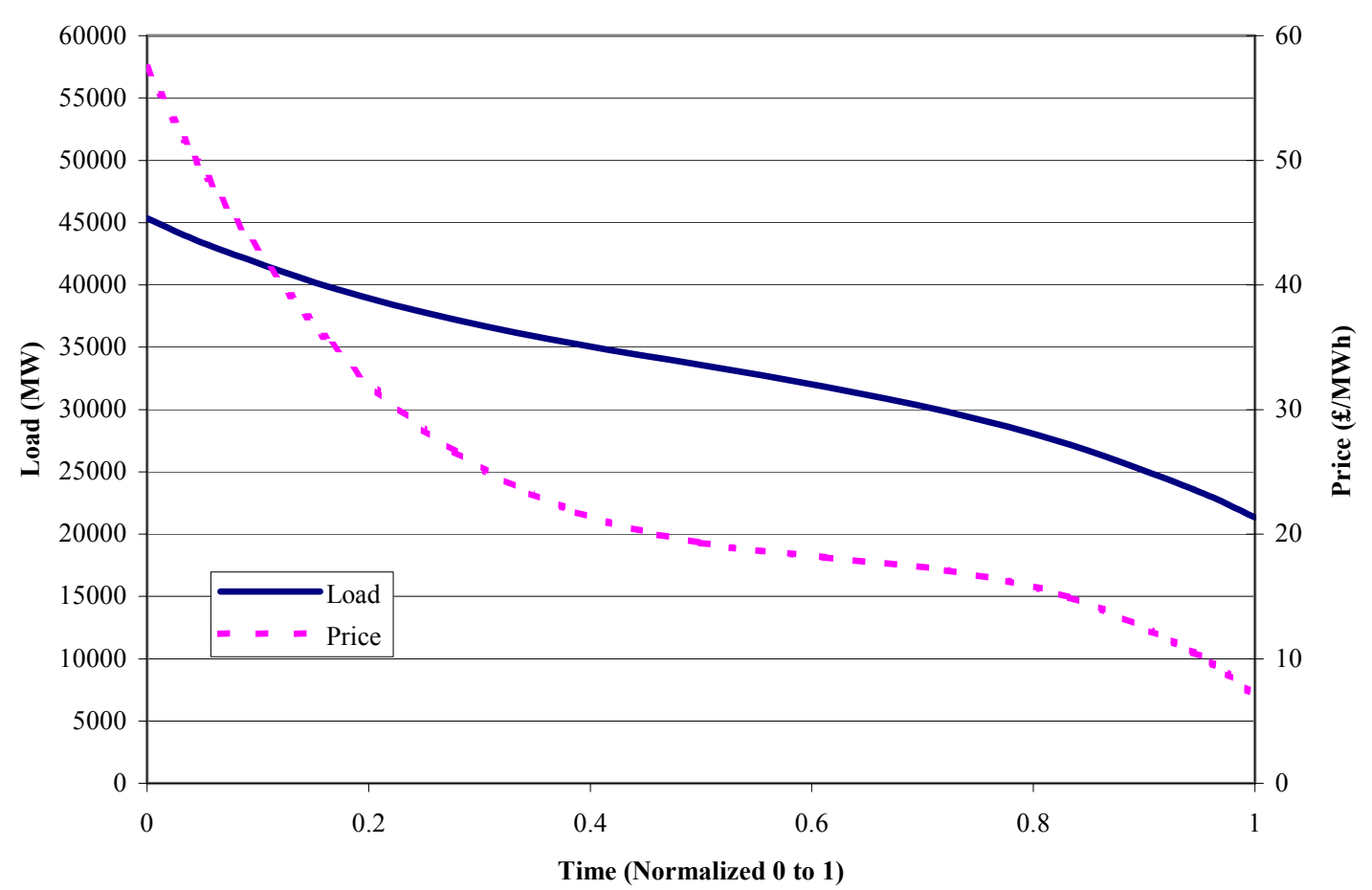

For the conditions studied by GN and Green (1996), the price-taking producers were never marginal. Therefore, Green (1996), for example, reduces the load duration curve by his estimate of constant inframarginal production and applies the LSFE to the residual demand. ${ }^{16}$

By 1999, however, growth in the capacity of IPPs and the increased availability of nuclear plant made the price-takers marginal during low demand periods. Incorporating this effect introduces the need to model capacity limits explicitly. The methods discussed in Section 3 are implemented in our estimates. Examples of how this works are given below. We also discuss the plausibility of the ad hoc piecewise affine model (11).

\subsection{Revisiting the 1996 Divestitures}

\footnotetext{
${ }^{16}$ We followed the same approach in section 3 for notational convenience. However, here we will report the actual demand and supply, not the residual demand.
} 
In this section, we examine the 1996 divestitures. Our chief interest is in showing how capacity constraints, cost intercepts, and demand curve representation affect numerical estimates. This is done by re-examining Green (1996), which we refer to as G96.

We first consider capacity constraints. There is no explicit notion of capacity in the G96 model, which amounts to the assumption of potentially infinite supply from any producer. Without an explicit mechanism to introduce maximum capacity limits, results may violate capacity constraints. Applying the G96 analysis to the 1996 divestiture results in violations of the divested plant capacity constraints under various assumptions of demand slope. This emphasizes the need to represent the capacity constraints explicitly in the model. All subsequent analysis will incorporate capacity constraints.

Table 4 shows the results for before and after the 1996 divestitures, with adjustment of demand intercepts and capacity constraints enforced. Both the cases for zero intercept and for unequal non-zero intercepts are shown. Average divestiture prices in table 4 are in the vicinity of the observed average of 23.7 pounds per MWh.

Table 4: Results for 1996 divestitures

\begin{tabular}{|l|c|c|c|c|}
\hline & $\begin{array}{c}\text { Demand Slope } \\
\mathrm{GW} /(£ / M W h)\end{array}$ & $\begin{array}{c}\text { Duopoly price } \\
(£ / M W h)\end{array}$ & $\begin{array}{c}\text { Divest to three } \\
\text { price (£/MWh })\end{array}$ & Average GW \\
\hline Zero Intercept & 0.10 & 36.2 & 23.5 & 32.8 \\
\hline & 0.25 & 26.5 & 20.8 & 33.4 \\
\hline & 0.50 & 22.7 & 19.8 & 34.6 \\
\hline Cost Intercepts & 0.10 & 38.4 & 26.1 & 32.6 \\
\hline & 0.25 & 29.2 & 23.8 & 32.8 \\
\hline & 0.50 & 25.1 & 22.5 & 33.3 \\
\hline
\end{tabular}

\subsection{The 1999 Divestitures}

In 1999, NP and PG each divested about 4000 MW of coal-fired plant. Their motivation was to meet regulatory requirements associated with their proposed vertical mergers. 
Table 2 shows that the U.S. firms AES and Edison Mission Energy (EME) acquired the divested plant. Both firms already had generation assets in the E\&W market; IPPs for AES and both IPPs and the pumped storage plants for EME. ${ }^{17}$ We use the LSFE framework to assess the price implications of these divestitures, and to compare the performance of the affine case with the case where the marginal cost curves must pass through the origin.

Table 5 shows the results of using the data in table 2 and the two versions of the cost curve for the strategic generators with gas and coal-fired plant. The cases labeled Zero Intercept assume that all cost curve pass through the origin. The Positive Intercept cases assume the cost intercept values in table 3. Our calculations assume that both AES and EME bid strategically. Because the price changes from divestiture are realized over an extended time, we have used the 1998-99 level of IPP capacity (i.e $7339 \mathrm{MW}$ ) for the three strategic firm game and the 1999-2000 level of capacity (i.e. $9721 \mathrm{MW}$ ) for the five strategic firm game.

Table 5: Base Case Price Results for 1999 Divestitures (f/MWh)

\begin{tabular}{|c|c|c|c|c|c|c|}
\hline & \multicolumn{3}{|c|}{ 1999-Five Firms } & \multicolumn{3}{|c|}{ 1998-Three Firms } \\
\hline $\begin{array}{c}\text { Demand } \\
\text { Slope } \\
(\mathrm{GW} / \\
(£ / \mathrm{MWh}))\end{array}$ & $\begin{array}{c}\text { Average } \\
\text { Price } \\
\text { (£/MWh) }\end{array}$ & $\begin{array}{l}\text { High Price } \\
(£ / M W h)\end{array}$ & $\begin{array}{l}\text { Low Price } \\
(£ / M W h)\end{array}$ & $\begin{array}{c}\text { Average } \\
\text { Price } \\
(£ / \mathrm{MWh})\end{array}$ & $\begin{array}{l}\text { High Price } \\
(£ / M W h)\end{array}$ & $\begin{array}{l}\text { Low Price } \\
(£ / M W h)\end{array}$ \\
\hline \multicolumn{7}{|c|}{ Zero Intercept } \\
\hline 0.10 & 15.5 & 27.3 & 7.4 & 23.5 & 51.3 & 8.0 \\
\hline 0.25 & 16.3 & 31.1 & 7.5 & 20.8 & 40.8 & 8.1 \\
\hline 0.50 & 17.1 & 34.4 & 7.7 & 19.8 & 38.0 & 8.2 \\
\hline \multicolumn{7}{|c|}{ Positive Intercept } \\
\hline 0.10 & 19.9 & 28.1 & 12.4 & 26.1 & 50.7 & 12.8 \\
\hline
\end{tabular}

\footnotetext{
${ }^{17}$ For simplicity, the pumped storage plant is neglected in these estimates. Much of that capacity supplies reserves. It is reasonable to ignore this factor in this kind of simple analysis of the energy market.
} 


\begin{tabular}{|l|l|l|l|l|l|l|}
\hline 0.25 & 19.9 & 29.3 & 12.3 & 23.8 & 41.2 & 12.7 \\
\hline 0.50 & 20.5 & 34.9 & 12.2 & 22.5 & 38.4 & 12.5 \\
\hline
\end{tabular}

Table 5 shows, for each case, the time-weighted average price, the highest price and the lowest price. The price change predictions of divestiture, i.e. the difference in average prices, are greater at low elasticity than at high elasticity regardless of the cost curve characterization. As expected, the biggest differences between the positive and zero intercept representation are at the low end of the price distribution.

In reality, the SMP dropped substantially in the 1999-2000 power year. Previously, the average SMP had been reasonably stable in the $£ 23-24$ /MWh range over many years. For the 1999-2000 power year the average SMP was $£ 20 .{ }^{18}$ This suggests that the estimates based on the positive intercept cases are better than those based on the zero intercept cases because the average prices for zero intercept are too low for the five-firm case.

Tables 6 and 7 show the quantity behavior (MWh produced per hour) of the firms for the cases with demand slope of $0.25 \mathrm{GW} /(\mathfrak{E} / \mathrm{MWh})$ for each cost curve characterization. Table 6 illustrates the zero intercept results and table 7 illustrates the positive intercept results.

Table 6a shows that the fringe firms (Nuclear, Interconnector and IPP) are marginal during periods 8 and 9 . This is indicated by shading the periods and indicating in bold that the fringe firm production is below the maximum levels achieved in higher demand periods. In table $6 \mathrm{~b}$, the fringe firms are marginal in period 7 as well as periods 8 and 9 .

Table 6a: Zero Intercept Case: 1998-Three Strategic Firms

\begin{tabular}{|c|c|c|c|c|c|c|c|c|c|c|}
\hline Time Period & Average & 1 & 2 & 3 & 4 & 5 & 6 & 7 & 8 & 9 \\
\hline $\begin{array}{r}\text { Price } \\
(\mathfrak{f} / \mathrm{MWh})\end{array}$ & 20.78 & 40.81 & 29.06 & 24.59 & 21.54 & 19.35 & 17.44 & 15.25 & 10.96 & 8.06 \\
\hline
\end{tabular}

\footnotetext{
${ }^{18}$ See data available at $h \mathrm{ttp}: / /$ www.elecpool.com/financial/financial_f.html. The SMP declined to $£ 18$ in the power year 2000-2001 following additional IPP entry and further divestiture.
} 


\begin{tabular}{|r|r|r|r|r|r|r|r|r|r|r|}
\hline Nuclear & 8,707 & 8,732 & 8,732 & 8,732 & 8,732 & 8,732 & 8,732 & 8,732 & 8,732 & $\mathbf{8 , 4 7 8}$ \\
\hline Interconnector & 3,075 & 3,136 & 3,136 & 3,136 & 3,136 & 3,136 & 3,136 & 3,136 & 3,136 & $\mathbf{2 , 5 7 9}$ \\
\hline IPP & 5,966 & 6,239 & 6,239 & 6,239 & 6,239 & 6,239 & 6,239 & 6,239 & $\mathbf{5 , 7 4 7}$ & $\mathbf{4 , 2 2 5}$ \\
\hline Eastern & 3,569 & 5,695 & 5,165 & 4,370 & 3,828 & 3,438 & 3,100 & 2,711 & 2,138 & 1,677 \\
\hline NP & 6,469 & 10,711 & 9,055 & 7,660 & 6,710 & 6,027 & 5,434 & 4,751 & 4,229 & 3,648 \\
\hline PG & 6,408 & 10,633 & 8,972 & 7,590 & 6,649 & 5,972 & 5,384 & 4,708 & 4,176 & 3,593 \\
\hline
\end{tabular}

Table 6b: Zero Intercept Case: 1999-Five Strategic Firms

\begin{tabular}{|r|r|r|r|r|r|r|r|r|r|r|}
\hline Time Period & Average & 1 & 2 & 3 & 4 & 5 & 6 & 7 & 8 & 9 \\
\hline $\begin{array}{r}\text { Price } \\
(\text { f/MWh) }\end{array}$ & 16.29 & 31.12 & 23.24 & 19.41 & 16.80 & 14.92 & 13.29 & 10.96 & 9.34 & 7.54 \\
\hline Nuclear & 8,643 & 8,732 & 8,732 & 8,732 & 8,732 & 8,732 & 8,732 & 8,732 & 8,732 & $\mathbf{7 , 9 3 2}$ \\
\hline Interconnector & 3,039 & 3,136 & 3,136 & 3,136 & 3,136 & 3,136 & 3,136 & 3,136 & $\mathbf{2 , 9 8 7}$ & $\mathbf{2 , 4 1 3}$ \\
\hline IPP & 7,655 & 8,262 & 8,262 & 8,262 & 8,262 & 8,262 & 8,262 & $\mathbf{7 , 6 0 7}$ & $\mathbf{6 , 4 8 2}$ & $\mathbf{5 , 2 3 5}$ \\
\hline Eastern & 3,012 & 5,350 & 4,273 & 3,568 & 3,088 & 2,743 & 2,443 & 2,181 & 1,891 & 1,576 \\
\hline AES & 1,882 & 3,315 & 2,704 & 2,258 & 1,954 & 1,736 & 1,546 & 1,333 & 1,147 & 944 \\
\hline NP & 4,715 & 7,893 & 6,631 & 5,537 & 4,792 & 4,256 & 3,791 & 3,619 & 3,185 & 2,732 \\
\hline PG & 4,481 & 7,568 & 6,312 & 5,271 & 4,561 & 4,052 & 3,608 & 3,409 & 2,994 & 2,556 \\
\hline EME & 1,882 & 3,315 & 2,704 & 2,258 & 1,954 & 1,736 & 1,546 & 1,333 & 1,147 & 944 \\
\hline
\end{tabular}

Tables $6 \mathrm{a}$ and $6 \mathrm{~b}$ indicate production by the coal based strategic firms even when the fringe firms are marginal. The prices in those periods, however, are below the minimum marginal costs of the coal plants; i.e. the assumed intercept of $£ 12 / \mathrm{MWh}$. The zero intercept formulation forces the plants to operate at prices that are below the intercept of their true marginal cost curves. By contrast, tables $7 \mathrm{a}$ and $7 \mathrm{~b}$ show production by coal based strategic firms declining toward zero as price falls toward the marginal cost minimum.

Table 7a: Positive Intercept Case: 1998-Three Strategic Firms

\begin{tabular}{|c|c|c|c|c|c|c|c|c|c|c|}
\hline Time Period & Average & 1 & 2 & 3 & 4 & 5 & 6 & 7 & 8 & 9 \\
\hline $\begin{array}{r}\text { Price } \\
(£ / M W h)\end{array}$ & 23.75 & 41.20 & 29.96 & 26.48 & 24.10 & 22.40 & 20.91 & 19.21 & 16.84 & 12.69 \\
\hline Nuclear & 8,732 & 8,732 & 8,732 & 8,732 & 8,732 & 8,732 & 8,732 & 8,732 & 8,732 & 8,732 \\
\hline Interconnector & 3,136 & 3,136 & 3,136 & 3,136 & 3,136 & 3,136 & 3,136 & 3,136 & 3,136 & 3,136 \\
\hline IPP & 6,186 & 6,239 & 6,239 & 6,239 & 6,239 & 6,239 & 6,239 & 6,239 & 6,239 & 5,732 \\
\hline Eastern & 2,986 & 5,695 & 4,960 & 3,997 & 3,342 & 2,871 & 2,461 & 1,990 & 1,336 & 223 \\
\hline $\mathrm{NP}$ & 6,230 & 10,657 & 9,043 & 7,608 & 6,631 & 5,928 & 5,317 & 4,615 & 3,639 & 2,628 \\
\hline
\end{tabular}




\begin{tabular}{|r|r|r|r|r|r|r|r|r|r|r|}
\hline $\mathrm{PG}$ & 6,177 & 10,590 & 8,964 & 7,542 & 6,573 & 5,876 & 5,271 & 4,575 & 3,607 & 2,592 \\
\hline
\end{tabular}

Table 7b: Positive Intercept Case: 1999-Five Strategic Firms

\begin{tabular}{|r|r|r|r|r|r|r|r|r|r|r|}
\hline Time Period & Average & 1 & 2 & 3 & 4 & 5 & 6 & 7 & 8 & 9 \\
\hline $\begin{array}{r}\text { Price } \\
(\mathfrak{f} / \mathrm{MWh})\end{array}$ & 19.88 & 29.32 & 25.29 & 22.51 & 20.61 & 19.25 & 18.06 & 16.70 & 14.80 & 12.34 \\
\hline Nuclear & 8,732 & 8,732 & 8,732 & 8,732 & 8,732 & 8,732 & 8,732 & 8,732 & 8,732 & 8,732 \\
\hline Interconnector & 3,136 & 3,136 & 3,136 & 3,136 & 3,136 & 3,136 & 3,136 & 3,136 & 3,136 & 3,136 \\
\hline IPP & 8,125 & 8,262 & 8,262 & 8,262 & 8,262 & 8,262 & 8,262 & 8,262 & 8,262 & 7,032 \\
\hline Eastern & 2,296 & 5,086 & 3,903 & 3,085 & 2,528 & 2,128 & 1,780 & 1,380 & 823 & 114 \\
\hline AES & 1,480 & 3,278 & 2,516 & 1,989 & 1,630 & 1,371 & 1,147 & 889 & 531 & 69 \\
\hline NP & 4,636 & 8,324 & 6,751 & 5,664 & 4,923 & 4,391 & 3,928 & 3,396 & 2,656 & 2,051 \\
\hline PG & 4,410 & 7,922 & 6,425 & 5,390 & 4,685 & 4,178 & 3,738 & 3,232 & 2,528 & 1,926 \\
\hline EME & 1,480 & 3,278 & 2,516 & 1,989 & 1,630 & 1,371 & 1,147 & 889 & 531 & 69 \\
\hline
\end{tabular}

The results in tables 5-7 show dramatic price effects from the 1999 divestitures, accentuated by the additional IPP capacity. At the low demand slope preferred by many authors, i.e. $0.10 \mathrm{GW} /(£ / \mathrm{MWh})$, the average prices in the pre-divestiture case are reasonable for the zero intercept case, but the price drop prediction is too great. The positive intercept case predicts a plausible post-divestiture price but is too high predivestiture compared to the observed level.

\subsection{The Earn Out Payments}

The data used for tables 5-7 neglects a particular point about Eastern's costs that came to public attention in 1997. This is the "earn-out" payments made by Eastern to NP and PG. Green and Newbery (1997) provide a discussion of this issue. The plant controlled by Eastern was actually leased from NP and PG, not purchased. Some of the lease payments were made on a variable basis at a rate of $£ 6 / \mathrm{MWh}$. This has the effect of increasing Eastern's marginal costs by this amount. It is interesting to test how the earn-out payments affect the equilibrium price. Table 8 reports the results of re-running the 1998three strategic firm game for the positive intercept case with the earn-out payment and also repeats the corresponding entries from table 5 without the earn-out payment. 
Table 8: 1998-Three Strategic Firm Market: Earn-out Sensitivity

\begin{tabular}{|c|c|c|c|c|c|c|}
\hline & \multicolumn{3}{|c|}{ Without Earn-out } & \multicolumn{3}{c|}{ With Earn-out } \\
\hline $\begin{array}{c}\text { Demand } \\
\text { Slope }\end{array}$ & $\begin{array}{c}\text { Average } \\
\text { Price }\end{array}$ & High Price & Low Price & $\begin{array}{c}\text { Average } \\
\text { Price }\end{array}$ & High Price & Low Price \\
\hline 0.10 & 26.1 & 50.7 & 12.8 & 26.4 & 37.4 & 18.4 \\
\hline 0.25 & 23.8 & 41.2 & 12.7 & 24.4 & 36.2 & 14.9 \\
\hline 0.50 & 22.5 & 38.4 & 12.5 & 23.2 & 36.1 & 12.6 \\
\hline
\end{tabular}

There are a number of interesting results in table 8 . First, the average prices are only slightly higher with than without earn-out. Second, for a given demand slope, the spread of prices are generally smaller with earn-out than without earn-out. The key driver of the earn-out results is that the earn-out payments raise Eastern's costs and hence its offer curve at low demand. This pushes Eastern's plants up in the loading order, so that their capacity is no longer at maximum in the high demand state. Without the earn out payment, Eastern reaches full capacity in Time Period $1^{19}$, so NP and PG can shift to a more inelastic supply curve and push the price up in that period (£41.2/MWh vs. $£ 36.2 / \mathrm{MWh}$ ). Table 9 shows these effects by tabulating the slopes of the supply curves for each strategic firm during the different time (load) periods for the Demand Slope $=$ 0.25 case.

Table 9: Supply Curve Slope (MW/(f/MWh))

\begin{tabular}{|l|l|c|c|c|}
\hline Case & Firm & Period 1 & Periods 2-8 & Period 9 \\
\hline No Earn-Out & Eastern & 0 & 276 & 325 \\
\hline & NP & 321 & 412 & 561 \\
\hline & PG & 319 & 408 & 553 \\
\hline Earn -Out & Eastern & 276 & 276 & 0 \\
\hline & NP & 412 & 412 & 321 \\
\hline & PG & 408 & 408 & 319 \\
\hline
\end{tabular}

\footnotetext{
${ }^{19}$ table 7a shows that Eastern's output in Time Period 1 is 5695 MW, which is its total nominal capacity adjusted downward for $85 \%$ availability.
} 
Table 9 shows that Eastern's supply function has zero slope in Period 1 without the EarnOut, because it is at maximum capacity. In this case, also, all strategic firms are more elastic in Period 9, when IPP capacity is marginal (see table 7a), than in Periods 2-8, when IPPs are at maximum capacity. In the Earn-Out case, the Period 9 price is below Eastern's marginal cost, so it does not produce. NP and PG can offer a less elastic supply in this period because Eastern is out of the market. They become more elastic when Eastern can produce, starting in Period 8. Since Eastern is not at maximum capacity with Earn-Out in Period 1, NP and PG cannot shift to the less elastic segment of their supply curve.

\subsection{Piece-wise Affine Supply Curves}

A final empirical point about the effect of capacity constraints on supply functions is illustrated in figure 5 . This figure corresponds to table $7 \mathrm{~b}$. It shows the supply functions of the five strategic firms constructed according to equations (9) and (11). Figure 5 shows prices in the range $£ 10 / \mathrm{MWh}$ to $£ 30 / \mathrm{MWh}$, which covers the range of realized prices. In this range, every firm except the IPP is either:

- always at capacity, or

- always marginal or off.

Consequently, the only maximum capacity reached in this range is the capacity of the IPP fringe capacity.

Recall that in (11) we posited zero slopes for the supply functions for the range of prices just below where the fringe reaches capacity. This accounts for the horizontal part of the supply curve in figure 5 between $£ 12 / \mathrm{MWh}$ and £13/MWh. 


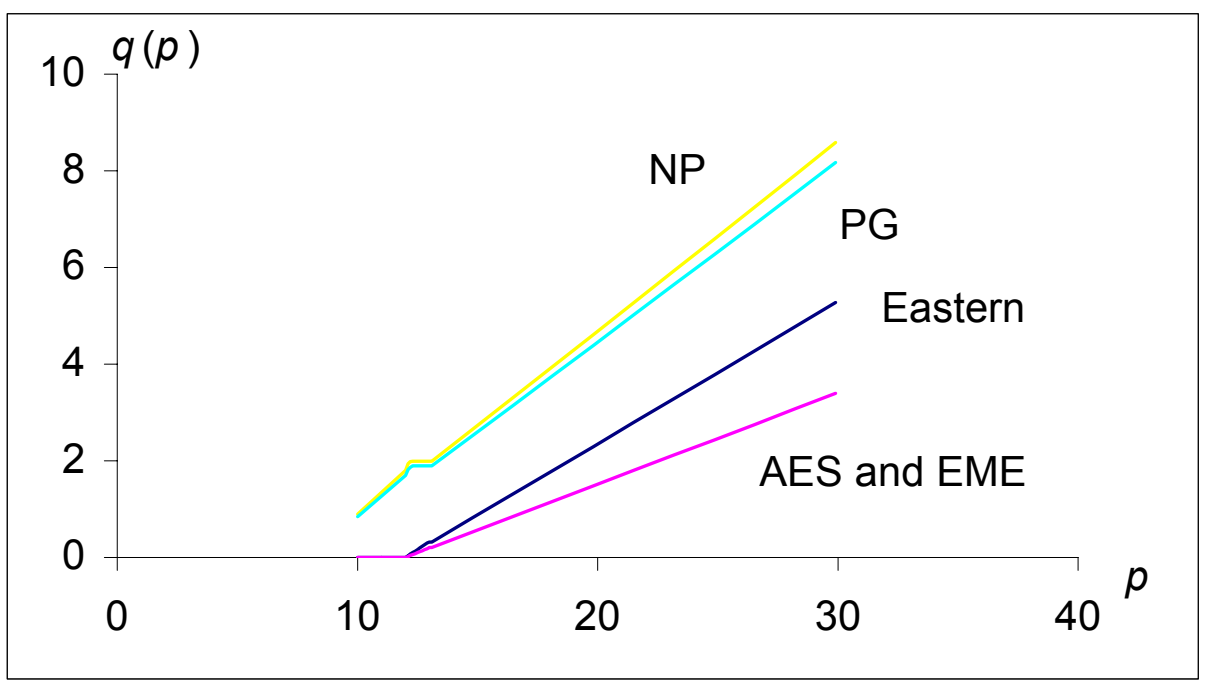

Figure 5: Piecewise affine supply curve constructed according to (9) and (11).

The supply functions are horizontal in a relatively small price range. This confirms the claim made in section 3 that the adjustment to the supply curve is relatively inconsequential in the overall supply curve. Numerical simulations in Baldick and Hogan (2002) to estimate the non-linear SFE are consistent with the general shape of the supply functions in figure 5 .

\section{CONCLUSIONS}

This paper has shown that the LSFE model generalizes readily to the affine case. We also introduce capacity constraints. Capacity constraints seem essential to model cases where fringe producers set the price for any demand periods. These constraints introduce discontinuities that are in some sense more extreme than similar phenomena in the Cournot framework. We propose an ad hoc approach to constructing piece-wise affine supply curves.

These theoretical properties are illustrated in a practical setting, namely the evolution of price behavior in the E\&W electricity market during periods of structural change. The 
affine case seems to fit the price behavior in the $\mathrm{E} \& \mathrm{~W}$ market better than the zero intercept case.

In future work we plan to consider the effect of price caps and analyze transmission constraints. The work of Berry et al. (1999) provides guidance in the consideration of transmission constraints.

\section{REFERENCES}

Alba, J., I. Otero-Novas, C. Meseguer and C. Batlle, "Competitor Behavior and Optimal Dispatch: Modelling Techniques for Decision-Making," The New Power Markets: Corporate Strategies for Risk and Reward. ed. R. Jameson, London: Risk Publications, 1999.

Andersson, B. and L. Bergman, "Market Structure and the Price of Electricity: An Ex Ante Analysis of the Deregulated Swedish Electricity Market," The Energy Journal 16(2) 97-130, 1995.

Baldick, R, R. Grant, and E. Kahn, “Linear Supply Function Equilibrium: Generalizations, Application, and Limitation,” POWER Working paper, 2000, available from www.ucei.berkeley.edu/ucei

Baldick, R. and W. W. Hogan, "Capacity Constrained Supply Function Equilibrium Models of Electricity Markets: Stability, Non-decreasing constraints, and Function Space Iterations," POWER Working paper, Revised August 2002, available from www.ucei.berkeley.edu/ucei

Berry, C. A, Hobbs, B. F., Meroney, W. A., O’Neill, R. P., and Stewart, W. R., "Understanding how market power can arise in network competition: a game theoretic approach," Utilities Policy, 8, 139-158, 1999. 
Bohn, R., A. Klevorick and C. Stalon, "Second Report on Market Issues in the California Power Exchange Energy Markets," prepared for the Federal Energy Regulatory Commission by the Market Monitoring Committee of the California Power Exchange, March, 1999.

Borenstein, S. and J. Bushnell, “An Empirical Analysis of the Potential for Market Power in California's Electricity Industry," Journal of Industrial Economics 47(3): 285-323, 1999.

Borenstein, S., J. Bushnell and S. Stoft, "The Competitive Effect of Transmission Capacity in a Deregulated Electricity Market," RAND Journal of Economics 2000.

Bunn, D. and C. Day, "Market Structure is Fundamental," Strategic Price Risk in Wholesale Power Markets, London: Risk Books, 1999.

Bushnell, J. “A Mixed Complementarity Model of Hydro-Thermal Electricity Competition in the Western U.S.," Operations Research (to appear 2002).

Day, C. J. and Bunn, D. W., "Divestiture of Generation Assets in the Electricity Pool of England and Wales: A Computational Approach to Analyzing Market Power," Journal of Regulatory Economics, 19(2), 123-141, 2001.

von der Fehr, N.-H. M. and Harbord, D., "Spot Market Competition in the UK Electricity Industry,” The Economic Journal, 103(418), 531-546, May 1993.

Frame, R. and P. Joskow, Testimony in State of New Jersey Board of Public Utilities Docket No. EX94120585Y and EO97070463, 1998.

Green, R. "Increasing Competition in the British Electricity Spot Market," Journal of Industrial Economics, 44(2), 205-216, 1996. 
Green, R. and D. Newbery, "Competition in the British Electricity Spot Market," Journal of Political Economy, 100(5), 929-953, 1992.

R Green and D. M. Newbery, "Competition in the electricity industry in England and Wales," Oxford Review of Economic Policy, 13: 27-46, 1997.

Hogan, W., "A Market Power Model With Strategic Interaction in Electricity Networks," The Energy Journal 18(4) 107-142, 1997.

Klemperer, P. and M. Meyer, "Supply Function Equilibria in Oligopoly Under Uncertainty," Econometrica 57 (1989) 1243-77.

Laussel, D., "Strategic Commercial Policy Revisited: A Supply-Function Equilibrium Model," American Economic Review 82(1) 1992, 84-99.

National Grid Company (NGC). Seven Year Statement, 1999.

Newbery, D., "Power Markets and Market Power," The Energy Journal, 16(3), 36-66, 1995.

Newbery, D. Privatization, Restructuring, and Regulation of Network Utilities. MIT Press, 1999.

Office of Electricity Regulation (OFFER), Report on Pool Prices Increases in Winter 1997/98, June, 1998.

Office of Electricity Regulation (OFFER), Rises in Pool Prices in July: A Decision Document, October, 1999. 
Ramos, A., M. Ventosa and M. Rivier, "Modeling Competition in Electric Energy Markets by Equilibrium Constraints," Utilities Policy, v.7, no.4 (1998) 223-242.

Rivier, M., M. Ventosa, A. Ramos, F. Martinez-Corcoles, and A. Chiarri, "A Generation Operation Planning Model in Deregulated Electricity Markets based on the Complementarity Problem," Proceedings of the International Conference on Complementarity Problems, Madison, Wisconsin, 1999.

Rothkopf, M., "Daily Repetition: A Neglected Factor in the Analysis of Electricity Auctions," The Electricity Journal, v.11 (1999) 60-70.

Rudkevich, A., "Supply function equilibrium in power markets: Learning all the way," TCA Technical Report Number 1299-1702, Tabors Caramanis and Associates, December 1999.

Rudkevich, A., M. Duckworth, R. Rosen "Modeling Electricity Pricing in a Deregulated Generation Industry: The Potential for Oligopoly Pricing in a Poolco," The Energy Journal, 19(3), 19--48, 1998.

Scott, T., "Hydro reservoir management for an electricity market with long term contracts," Ph.D. thesis, University of Canterbury, Department of Management, 1997.

Scott, T. and G. Read, "Modeling Hydro Reservoir Operation in a Deregulated Electricity Market," International Transactions in Operations Research 3(3) 243-253, 1996.

Turnbull, S. J., "Choosing duopoly solutions by consistent conjectures and by uncertainty," Economics Letters, 13, 253-258, 1983. 


\section{ACKNOWLEDGMENT}

The first and third authors would like to thank Professor Severin Borenstein for his

hospitality during visits to the University of California Energy Institute in Summer 2000. The first author was funded in part by the National Science Foundation under grant ECS9457133 and by a grant from Tabors Caramanis and Associates. The authors would like to thank Dr. Huifu Xu and the anonymous referees for their comments. 


\section{APPENDIX. COST SLOPE PARAMETERS}

The cost slope parameters for tables 4, 5, 6 are given in table A.

Table A: Cost slope parameters for tables 4, 5, 6

\begin{tabular}{|l|c|c|c|c|}
\hline & $\begin{array}{c}1996 \text { pre- } \\
\text { divestiture }\end{array}$ & $\begin{array}{c}1996 \text { post- } \\
\text { divestiture }\end{array}$ & 1998 & 1999 \\
\hline IPPs & 0.002800 & 0.001907 & 0.000817 & 0.000617 \\
\hline NP & 0.000957 & 0.001358 & 0.001358 & 0.001789 \\
\hline PG & 0.001167 & 0.001384 & 0.001384 & 0.001930 \\
\hline Eastern & & 0.002687 & 0.002687 & 0.002687 \\
\hline EME, AES & & & & 0.004615 \\
\hline
\end{tabular}

